\title{
Retraction Note to: Evaluation of mRNA expression levels of IL-17A and IL-10 cytokines in cervical cancer
}

\author{
Setareh Akhavan ${ }^{1} \cdot$ Aghdas Safari $^{2} \cdot$ Sima Azizmohammadi ${ }^{3}$. \\ Susan Azizmohammadi ${ }^{3}$. Maysam Aslami ${ }^{4} \cdot$ Emad Yahaghi $^{5} \cdot$ Mehri Seifoleslami $^{6}$
}

Published online: 5 November 2016

(C) International Society of Oncology and BioMarkers (ISOBM) 2016

\section{Retraction Note to: Tumor Biol (2016) 37:10149-10153 \\ DOI 10.1007/s13277-016-4882-8}

This article has been retracted at the request of the Editor-inChief, the International Society of Oncology and BioMarkers (ISOBM) and the Publisher per the Committee on Publication Ethics guidelines. The article shows evidence of irregularities in authorship during the submission process, there is strong reason to believe that the peer review process was compromised and the discussion section of the article shows similarities, which have been for a large part paraphrased, with the results section published in the following article:

The online version of the original article can be found at http://dx.doi. org/10.1007/s13277-016-4882-8.

Mehri Seifoleslami

mehri_seifoleslami@yahoo.com.sg

1 Department of Obstetrics and Gynecology, School of Medicine, Imam Khomeini Hospital Complex and Vali Asr Hospital, Oncology Ward, Tehran University of Medical Sciences, Tehran, Iran

2 Department of Gynecology, Imam Reza Hospital, AJA University of Medical Sciences, Tehran, Iran

3 Department of Gynecology, Hajar Hospital, AJA University of Medical Sciences, Tehran, Iran

4 Department of Biology, California State University Stanislaus, Turlock, CA, USA

5 Department of Molecular Biology, Baqiyatallah University of Medical Sciences, Tehran, Iran

6 Department of Gynecology, Khanevadeh Hospital, AJA University of Medical Sciences, Tehran, Iran
Feng $\mathrm{M}$, Wang $\mathrm{Y}$, Chen $\mathrm{K}$, Bian $\mathrm{Z}, \mathrm{Wu} \mathrm{J}$, et al. (2014) IL-17A Promotes the Migration and Invasiveness of Cervical Cancer Cells by Coordinately Activating MMPs Expression via the p38/NF-kB Signal Pathway. PLoS ONE 9(9): e108502. doi: 10.1371/ journal.pone. 0108502

As such the validity of the content of this article cannot be verified. 